\title{
Emerson, Gibala, Ross, and Schowalter to Chair 1998 MRS Spring Meeting
}

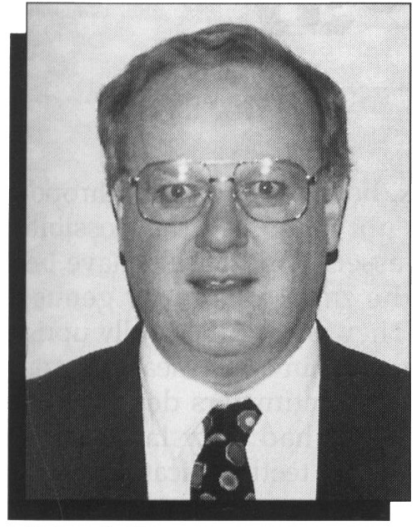

John A. Emerson

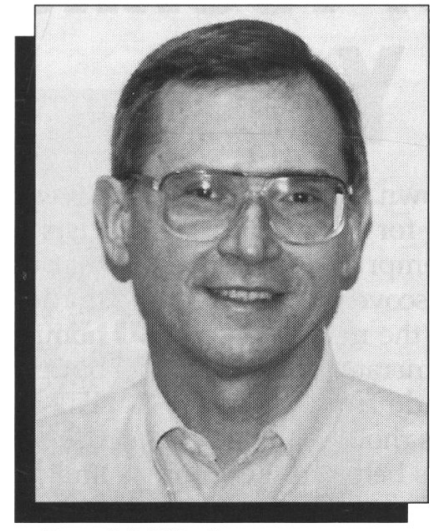

Ronald Gibala

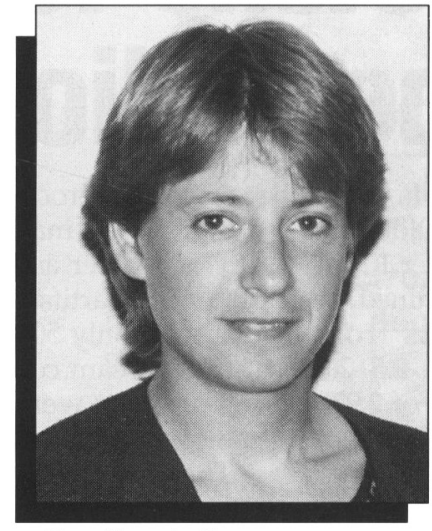

Caroline A. Ross

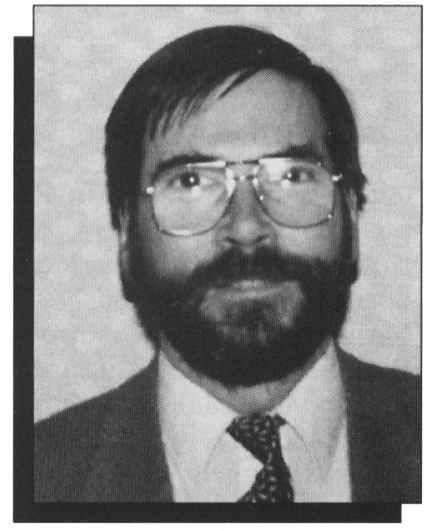

Leo J. Schowalter
The 1998 Spring Meeting of the Materials Research Society will be held in San Francisco on April 13-17 1998, and will be chaired by John A. Emerson, Ronald Gibala, Caroline A. Ross, and Leo J. Schowalter. The meeting will include 32 symposia covering a range of topics in materials science, including both wellestablished symposium series and new topics. Several new symposia on microelectronic device materials include Materials Issues in Vacuum Microelectronics, Organic Electroluminescent Devices, Reliability of Photonic Materials, and Chemical-Mechanical Polishing. There will also be new symposia in exciting areas such as Microelectromechanical Structures for Materials Research, Nanoindentation and Nanotribology, Scanning Microprobes, Biomaterials and Tissue Engineering, Magneto-Optical Materials, and Materials for High-Density Magnetic Storage. Polymer/Ceramic Microstructures, Organometallics, Biomaterials, and Porous and Cellular Materials will each have a dedicated symposium. There will be symposia on Epitaxial Growth in Metallic Systems, Epitaxy in Silicon-Based Heterostructures, and Diffusion Mechanisms in Crystalline Materials. Several tutorial sessions will provide a detailed introduction to particular symposium subject areas. There will be an exhibit of products and services of interest to the materials community. The popular Symposium $X$ will provide lunchtime talks on historical topics regarding the development of the semiconductor industry.

John A. Emerson is a senior member of technical staff in the Organic Materials Department at Sandia National Laboratories. He received a $\mathrm{PhD}$ degree from
Rensselaer Polytechnic Institute on the subject of gas phase chemical kinetics, then worked as a postdoctoral fellow at AeroChem with Arthur Fontijn on hightemperature gas-phase reactions. He spent 22 years at Bell Laboratories' Engineering Research Center in Princeton conducting research on relating polymer properties to their structure for several large-scale production processes. His work included the use of manufacturing engineering science to enhance production processes for organic materials such as polymers and their interfaces. In the last five years his work at Sandia has dealt with science of adhesion between polymers and metal surfaces, understanding the physics of the flow of highly-filled polymers in thin gaps, and technology for encapsulating microelectronic devices.

Ronald Gibala is a professor in and former chair of the Department of Materials Science and Engineering at the University of Michigan. He directs the Center for High Temperature Structural Metallic Materials. His current research interests are in the area of mechanical behavior of materials, particularly intermetallic alloys and related quasi-brittle materials.

After receiving his $\mathrm{PhD}$ degree in metallurgical engineering from the University of Illinois at Urbana-Champaign, Gibala taught at Case Western Reserve University from 1964 to 1984 and was associate director and director of the CWRU Materials Research Laboratory during the latter part of that time. Gibala served as councillor on the MRS Executive Committee in 1996 and was re-appointed in 1997.

Caroline A. Ross is an assistant professor in the Department of Materials
Science and Engineering at Massachusetts Institute of Technology. She received a $\mathrm{PhD}$ degree in electromigration in thin film metallization from Cambridge University, then worked as a postdoctoral fellow at Harvard University on electrodeposited multilayer films. She spent six years as an engineer at Komag Inc., conducting research on the magnetic and mechanical properties of materials used in hard disks. Her research interests include the magnetic properties of thin films used for data storage, magnetic properties of patterned structures, and internal stress and mechanical properties of thin films. She has co-organized two MRS symposia, one on Stresses and Mechanical Properties and one on Polycrystalline Thin Films.

Leo J. Schowalter is a professor in the Physics, Applied Physics, and Astronomy Department and is also an associate director of the Center for Integrated Electronics and Electronics Manufacturing at the Rensselaer Polytechnic Institute. He received his $\mathrm{PhD}$ degree in physics from the University of Illinois at UrbanaChampaign. He was then employed by the GE Research and Development Center in Schenectady where he worked primarily in molecular beam epitaxy of semiconductor structures. He joined RPI in 1987 and continues to be involved in heteroepitaxial growth and in the characterization of these materials. His interests focus on the development of opto-electronic materials for optical interconnects and other photonic applications and on the study of hot carrier (ballistic) transport across interfaces. Schowalter was recently guest editor of the April 1996 MRS Bulletin and he is chair of the MRS Tutorial Subcommittee. 